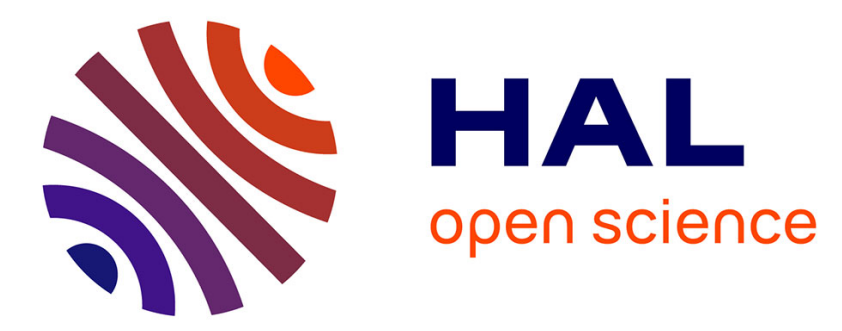

\title{
Temperature distributions of solid particles in a plasma stream
}

\author{
B. Kruszewska, J. Lesinski
}

\section{To cite this version:}

B. Kruszewska, J. Lesinski. Temperature distributions of solid particles in a plasma stream. Revue de Physique Appliquée, 1977, 12 (9), pp.1209-1211. 10.1051/rphysap:019770012090120900 . jpa00244300

\section{HAL Id: jpa-00244300 https://hal.science/jpa-00244300}

Submitted on 1 Jan 1977

HAL is a multi-disciplinary open access archive for the deposit and dissemination of scientific research documents, whether they are published or not. The documents may come from teaching and research institutions in France or abroad, or from public or private research centers.
L'archive ouverte pluridisciplinaire HAL, est destinée au dépôt et à la diffusion de documents scientifiques de niveau recherche, publiés ou non, émanant des établissements d'enseignement et de recherche français ou étrangers, des laboratoires publics ou privés. 
Classification

Physics Abstracts

52.70

\title{
TEMPERATURE DISTRIBUTIONS OF SOLID PARTICLES IN A PLASMA STREAM $(*)(* *)$
}

\author{
B. KRUSZEWSKA and J. LESINSKI \\ Institute of Nuclear Research, Plasma Physics Departement, 05-400, Otwock, Poland
}

(Reçu le 30 décembre 1976, accepté le 17 mai 1977)

\begin{abstract}
Résumé. - On a présenté une nouvelle méthode d'analyse statistique de la température des particules solides dans le jet de plasma, le système de mesures et la méthode d'étalonnage. On a mesuré la distribution de température des grains d' $\mathrm{Al}_{2} \mathrm{O}_{3}$ projetés dans un plasma d'argon-hydrogène.
\end{abstract}

Abstract. - An original method for the statistical analysis of the temperature of solid particles in a plasma stream is presented. The apparatus and calibration method are described. Temperature distributions of $\mathrm{Al}_{2} \mathrm{O}_{3}$ particles sprayed in an argon-hydrogen plasma were investigated.

1. Introduction. - Previous papers concerning measurements of the temperature of the particles suspended in high temperature streams can be divided into two groups. The first, comprises papers in which authors measured the mean temperature of the stream of particles. They used different versions of the colour pyrometry method i. e. analyzing the spectral distributions of the thermal radiation of a multiparticle system $[2,3,4,5]$. The second group comprises a number of papers, in which authors measured the temperatures of single particles $[6,7,8,9]$. Particles having various temperatures are usually present in the stream. This results from the different trajectories in the jet which, in turn, are caused by the initial velocity and diameter distributions [1]. Therefore, only the discrete statistical analysis of particle temperatures enables investigation and optimization of the heating (and accelerating) conditions of particles in the plasma stream to be made. When photographic detection is employed to determine the total radiation intensity of particles moving so fast that during the exposure time they move a distance much greater than their diameter, the recorded intensity is not only dependent on temperature but also on the ratio of particle diameter to its velocity. English [9] used the discrete version of the colour pyrometry method. The radiation of a single particle passing through the slit was analysed by two photomultipliers operating in two spectral regions and two pulses were recorded with the aid of a double beam oscilloscope. The ratio of the amplitudes of these

$\left({ }^{*}\right)$ This work was done in coorperation between the Centre des Etudes Nucléaires, Grenoble, France and Institute of Nuclear Research, Swierk, Poland.

$\left({ }^{* *}\right)$ Communication presented at the Congrès National de Physique des Plasmas, Paris 6-10 decembre 1976. pulses is a function of the temperature of the particle and is independent of its diameter and velocity. In the already mentioned paper [9] combusted, pulverized coal had a broad distribution of particle size but an almost uniform temperature.

Size tolerance of powders used for plasma spraying is usually narrow, so that one can assume that all the particles have nearly the same diameter. Therefore, the intensities of the radiation emitted from the surface of single particles of known diameter give information about their temperature distribution.

2. Experiment. - The apparatus shown schematically in figure 1 was used for the analysis of tempera-

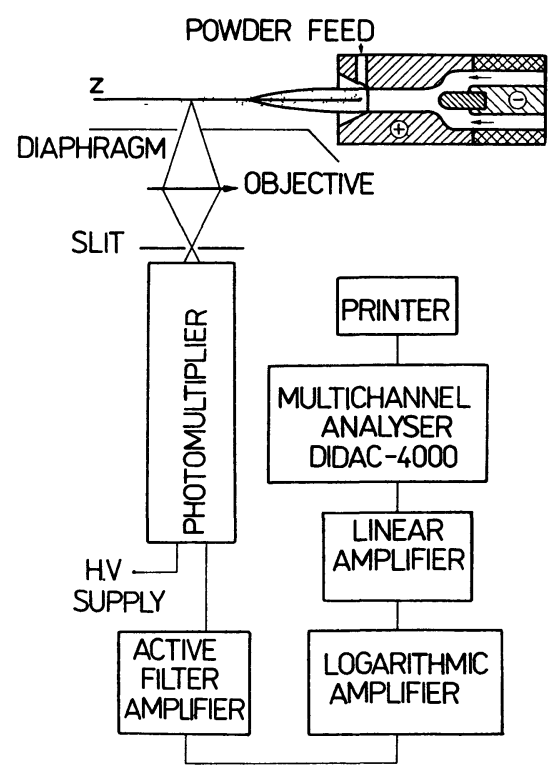

FIG. 1. - Diagram of apparatus of the multichannel analyser used for the evaluation of the particle temperatures 
tures of particles during the process of plasma spraying. Images of particles passing across the narrow slit situated in front of the photomultiplier give pulses whose amplitudes are proportional to the intensities of surface radiation integrated over the spectral region of the photomultiplier sensitivity. The photomultiplier has a photocathode sensitive to near infrared (type S1). Thus, pulses after amplification using the logarithmic amplifier are analysed by a multichannel analyser, an Intertechnique DIDAC 4000. The analyser gives the distribution of pulse amplitudes i. e. the count rate per unit of amplitude (channel width) as a function of the amplitude.

The calibration of the apparatus consists in finding the correlation between the particle temperature and the pulse amplitude for a fixed particle diameter. In practice, particles with a well known temperature and diameter and a suitable velocity are not available. Therefore they have to be simulated.

The system employed to simulate the stream of particles comprises a pin-hole, a tungsten ribbon lamp and a chopper. The pin-hole, imitating the particle is placed over the slit. The lamp with a well-known filament temperature is substituted for the source of radiation. The chopper of suitable velocity is placed in front of the slit. In this way the particle of known diameter, temperature and velocity is simulated. By changing the current of the lamp (temperature) the numbers of the particular channels of the multichannel analyser are determined in degrees. In spite of the logarithmic amplification, the calibration curve (particle temperature vs. analyser channel number) is not strictly linear. Thus it is necessary in quantitative analysis, to calculate temperature distributions from distributions of amplitudes obtained directly from the multichannel analyser. For qualitative analysis this is not necessary. The apparatus described allows measurements to be made of temperatures higher than $1900 \mathrm{~K}$ for particles about $50 \mu \mathrm{m}$ in diameter. The limitation is caused by radiation of the plasma jet scattered in the system and by the radiation of hot gas surrounding the particles. Spectral emissivities of tungsten (calibration) and $\mathrm{Al}_{2} \mathrm{O}_{3}$ up to the melting point were taken into account. Spectral emissivities of liquid $\mathrm{Al}_{2} \mathrm{O}_{3}$ were extrapolated. The melting point of $\mathrm{Al}_{2} \mathrm{O}_{3}$ is about $2300 \mathrm{~K}$, while the boiling point is about $3250 \mathrm{~K}$.

Temperature distributions of $\mathrm{Al}_{2} \mathrm{O}_{9} \cdot \mathrm{TiO}_{2} 3 \%$ particles of average size of $47 \mu \mathrm{m}$ and $63 \mu \mathrm{m}$ sprayed with the PN-110 PLANCER plasmatron have been measured.

The simplified diagram of the plasmatron is shown in figure 1. The powder was injected into the plasma jet perpendicular to the axis of the nozzle through the channel of $2 \mathrm{~mm}$ diameter. The mean initial velocity of the particles depended on the flow rate of the carrier gas. The dependence of temperature distribution of the particles on the distance from the nozzle and on the initial velocity of the particles was investigated. In order to obtain one temperature distribution, approximately one million particles were analysed during two minutes.

3. Results. - The temperature distributions of particles of $47 \mu \mathrm{m}$ average diameter are shown in figure 2 for a distance of $150 \mathrm{~mm}$ from the nozzle with

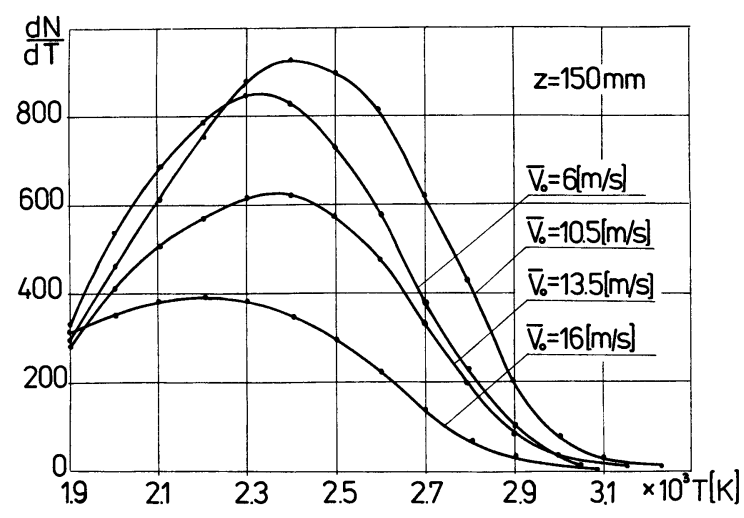

FIG. 2. - Temperature distribution of $47 \mu \mathrm{m}$ particles with initial velocity as a parameter Operating parameters of the plasmatron : $P-29.8[\mathrm{~kW}] ; I-500[\mathrm{~A}]$;

$$
f_{\mathrm{Ar}_{+} \mathrm{H}_{2}}-2890[\mathrm{Nl} / \mathrm{h}] ; \alpha-19[\%] \text {. }
$$

the initial velocity as a parameter. One can observe displacement of the maxima of temperature distributions and also that the initial velocity favourable for plasma spraying is about $10 \mathrm{~m} / \mathrm{s}$.

The temperature distributions of particles of a larger average diameter for the same distance from the nozzle and a higher input power of the plasmatron are shown in figure 3 . In this case the advantageous initial particle

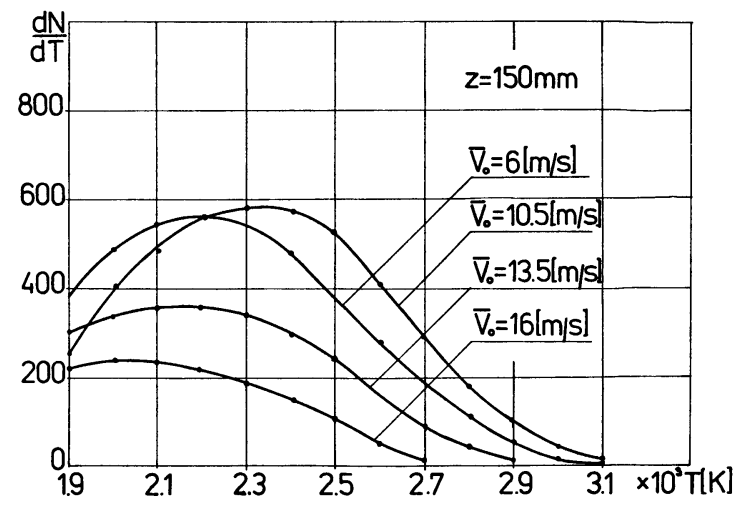

FIG. 3. - Temperature distribution of $63 \mu \mathrm{m}$ particles with initial velocity as a parameter Operating parameters of the plasmatron : $P-31.9[\mathrm{~kW}] ; I-500[\mathrm{~A}]$;

$$
f_{\mathrm{Ar}_{+} \mathrm{H}_{2}}-3040[\mathrm{Nl} / \mathrm{h}] ; \alpha-23[\%] \text {. }
$$

velocity is also approximately $10 \mathrm{~m} / \mathrm{s}$. In spite of the higher power consumption the temperatures of larger particles are lower than those of the smaller ones.

Also the cooling down of the stream of particles can be observed. An example is shown in figure 4 where the 


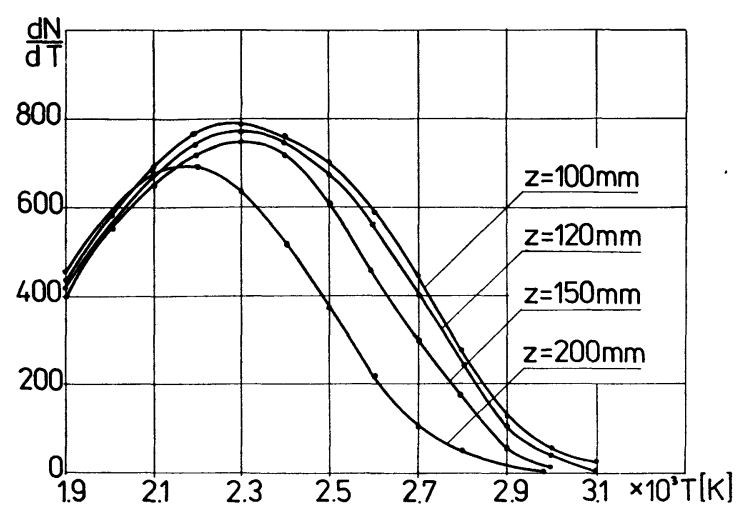

FIG. 4. - Temperature distribution of $63 \mu \mathrm{m}$ particles with the distance from the nozzle as a parameter Operating parameters of the plasmatron : $P-31.9[\mathrm{~kW}] ; I-500[\mathrm{~A}]$;

$$
f_{\mathrm{Ar}_{+} \mathrm{H}_{2}}-3040[\mathrm{Nl} / \mathrm{h}] ; \alpha-23[\%] \text {. }
$$

temperature distributions of particles are plotted with the distance from the nozzle as a parameter. This clearly shows that the particles with higher temperatures cool down more quickly then those with lower temperatures.

The sources of systematic errors are : unsatisfactory knowledge of the particle emissivities (especially at the highest temperatures) and a variation of particle diameters during the process itself. The source of statistical errors are : electronic noise, noise from the radiation fluctuation of hot gases, coincidences and differences of particle diameters.

The error analysis shows that the most important effects are the differences of the particle diameters; e. g. particles of $38-45 \mu \mathrm{m}$ in diameter at a temperature of $2500 \mathrm{~K}$ give pulse rates differing by an amount corresponding to a temperature difference of $100 \mathrm{~K}$.
4. Conclusion. - The powder is introduced into the plasmatron through the channel perpendicular to the axis of the plasma jet. Therefore, wide distributions of particle temperature are observed. These distributions depend strongly on the initial velocity of the powder. The initial velocity of the powder is a very important parameter of the plasma spraying process and should be optimised. A large number of particles (more than 50 percent) are melted in the stream when the operating parameters of the plasmatron and the powder feeder are optimised.

The proposed method for the analysis of temperature distributions of solid (liquid) particles in the stream may be used to investigate the heat exchange between the plasma and particles in a statistical manner. This method applied to the plasma spraying process allows the powder injection, spraying distance and operating parameters of the plasmatron to be optimised. The large number of particles analysed during one measurement gives a very good statistical value. Continuous visualization of data on the monitor of the analyser allows the operating parameters to be optimised in a quick and easy way.

\section{Glossary of symbols.}

$\bar{V}_{0} \quad$ the average initial particle velocity.

$z \quad$ the distance from the plasmatron nozzle.

$T \quad$ particle temperature.

$\mathrm{d} N$ the ratio of quantity of particles per unit $\overline{\mathrm{d} T}$ temperature.

$f_{\mathrm{Ar}+\mathrm{H}_{2}}$ flow rate of argon-hydrogen mixture in normal liters per hour.

$\alpha \quad$ hydrogen content in mixture in percent.

$P \quad$ input power in kilowatts.

$I \quad$ current in amperes.

\section{References}

[1] Fiszdon, J., Lesinski, J., Proc. Int. Round Table on Study and Applications of Transport Phenomena in Thermal Plasmas, Odeillo, France, 1975, paper IV-1.

[2] Hantzsche, H., Proc. 7th Int. Conf. on Metalisation London, 1973, paper 16

[3] Shimanovich, V. D., Shipai, A. K., Soloviov, B. M., Puzriakov, A. F., Proc. Conf. Fizika, Technika $i$ Primenenije Nizkotemperaturnoj Plazmy, Alma-Ata, USSR, 1970, p. 209.

[4] Antonov, G. S., Loskutov, V. S., Soloviov, B. M., ShimaNovich, V. D., SHIPAI, A. K., "Generatory Nizkotemperaturnoj Plazmy» (Energia, Moskow, USSR), 1969 , p. 490
[5] Nikolaiev, A. V., ibidem, p. 572.

[6] Gurevich, M. A., Dresvin, S. V., Kalganova, J. V., Klubnikin, V. S., Nizkovski, A. A., « Voprosy Fiziki Nizkotemperaturnoj Plazmy», (Nauka i Technika, Minsk, USSR), 1970, p. 580.

[7] Dresvin, S. V., Kalganova, J. V., Proc. Conf. Fizika, Technika $i$ Primenenije Nizkotemperaturnoj Plazmy, Alma-Ata, USSR, 1970, p. 617.

[8] Gurevich, M. A., Steinberg, V. B., J. Techn. Phys. USSR, XXVIII (1958) 394.

[9] English, P. E., Acta Imeco, 1967, p. 469. 